\title{
Effect of age at first farrowing and of litter size on the productive life of the sow
}

\author{
J.L. NOGUERA *, R. GUEBLEZ ** \\ *I.N.R.A., Station de Génétique quantitative et appliquée, 78350 Jotiy-en-Josas \\ :"*: I.T.P., B.P. 3, Domaine de la «Motte-aut-Vicomte», 35650 Lo'Rheu \\ France
}

Data from the "National computerized Programme for management of sow herds » involving 12432 sows in 1979 and belonging to 517 herds were used to study the effect of age at 1st farrowing (between 290 and 430 days) and that of 1 st litter size on the sow productive life.

- These two factors affected significantly and without interaction both the rotal number of born piglets and the total number of litters.

- When the age at first farrowing increased, the total number of born piglets decreased : this was only due to a decrease in the number of litters, the mean litter size being steady. The role of the biological factors was difficult to assess. The mortality rate before weaning changed little.

- The total number of born piglets increased with the size of the 1st litter without modifying the number of litters. The prolificacy differences between sows according to the first litter size were small for the subsequent litters. The mortality rate before weaning increased noticeably.

These two factors were responsible for marked variations in the numerical productivity and the piglet cost price, but the differences observed were mainly due to the results at 1st farrowing; it is therefore very important to find the best way to obtain an early farrowing and a good litter size. The effect of age at first mating should be studied to formulate practical recommendations.

\section{Variations in prolificacy between the first and the second litter}

\author{
J. DAGORN *, J. SAULNIER *, P. GREAU ** \\ *Institut Technique du Porc, B.P. 3, 35650 Le Rheu \\ *: Etablissement départemental de l'Elevage, \\ 9, rue de l'Ancien-Evêché, 53000 Laval
}

France

Prolificacy of the 60297 sows born in 1972 and 1973 was 9.72 piglets ( total born 》) in the first eycle (C1) and 10.36 in the second cycle (C2). The decrease in prolificacy in C2 concerned 20.5 p. 100 of the results per herd. Prolificacy of the 33814 sows born in 1979 and 1980 was 10.17 and 10.45 piglets, respectively in $\mathrm{Cl}$ and $\mathrm{C} 2$. The decrease in prolificacy in $\mathrm{C} 2$ concerned 33 p. 100 of the herds.

As regards the individual sow:

- Litter size in $\mathrm{C} 1$ had a large effect on prolificacy in $\mathrm{C} 2$. Eleven piglets and more in $\mathrm{C} 1$ led on an average to a decrease in $\mathrm{C} 2$.

- An increase in piolificacy of 1.18 piglet in $\mathrm{C} 2$ was observed when the first weaning-fertilization interval ranged between 20 and 40 days versus 0.01 piglet when the weaning-fertilization interval was shorter than 20 days.

Within a few years, prolificacy has increased by about 0.45 piglet. However, the stagnation in the second litter represents an important loss in earnings whose causes are discussed. It might be due to nutritional factors since the lipid reserves of the primiparous sows have been strongly reduced by selection. Further studies on lactation metabolism of primiparous sows in connection with the nature of the tissues involved, are required. 